\title{
Association of visceral adiposity and insulin resistance with colorectal adenoma and colorectal cancer
}

\author{
In Sub Jung ${ }^{1}$, Cheol Min Shin ${ }^{1}$, Sung Jae Park ${ }^{1}$, Young Soo Park ${ }^{1}$, Hyuk Yoon ${ }^{1}$, Hyun Jin Jo ${ }^{1,2}$, Nayoung Kim ${ }^{1}$, \\ Dong Ho Lee ${ }^{1}$ \\ ${ }^{1}$ Department of Internal Medicine and ${ }^{2}$ Health Promotion Center, Seoul National University Bundang Hospital, Seongnam, Korea
}

\begin{abstract}
Background/Aims: To examine whether visceral adiposity serves as a risk factor for colorectal cancer (CRC) and colorectal adenomas. Methods: Two hundred healthy subjects, 200 patients with colorectal adenoma, and 151 patients with CRC (46 with early-stage and 105 with advanced-stage cancers) were enrolled at a tertiary referral hospital. All subjects underwent colonoscopy, and had laboratory data, and computed tomography (CT) scan available for abdominal fat measurement. An abdominal CT scan taken 1 to 4 years (mean interval, 20.6 months) before the diagnosis of CRC was also available in the 42 CRC patients. Results: The mean areas of visceral adipose tissue (VAT) areas in the control, adenoma, early- and advanced-stage CRC groups were 94.6, 116.8, 110.4, and $99.7 \mathrm{~cm}^{2}$, respectively $(P<0.001)$. The risk of adenoma positively correlated with VAT area and the visceral-to-total fat ratio ( $P$ for trend $<0.01$ ), but the risk of CRC did not $(P>0.05)$. The risk of both adenoma and CRC positively correlated with fasting plasma glucose levels $(P$ for trend $<0.05)$. In patients with early-stage cancer $(n=17)$, VAT area decreased when the CT scan at diagnosis was compared with that taken before the diagnosis of CRC, but superficial adipose tissue area did not, so visceral-to-total fat ratio significantly decreased ( $46.6 \%$ vs. $50.7 \%$, respectively, $P=0.018$ ) Conclusions: VAT area is related to the risk of colorectal adenoma. However, VAT decreases from the early stages of CRC. Impaired fasting glucose has a role in colorectal carcinogenesis. (Intest Res 2019;17:404-412)
\end{abstract}

Key Words: Adipose tissue; Intra-abdominal fat; Obesity; Colorectal neoplasms; Tomography, X-ray computed

\section{INTRODUCTION}

Obesity significantly increases the risk of colorectal cancer (CRC) ${ }^{1,2}$ However, the underlying mechanisms are still unclear. Insulin resistance and altered levels of adipocytokines might have a role in obesity-induced colorectal carcinogenesis. $^{2}$ Insulin resistance increases the risk of CRC, and insulinlike growth factor-1 seems to have a key role in the relationship between insulin resistance and CRC. ${ }^{3}$ Obesity can directly cause chronic mild inflammation of the colonic mucosae

Received May 22, 2018. Revised August 29, 2018.

Accepted October 1, 2018.

Correspondence to Cheol Min Shin, Department of Internal Medicine, Seoul National University Bundang Hospital, 82 Gumi-ro 173beon-gil, Bundang-

gu, Seongnam 13620, Korea. Tel: +82-31-787-7057, Fax: +82-31-787-4052,

E-mail:scm6md@gmail.com

ORCID Cheol Min Shin (https://orcid.org/ 0000-0003-2265-9845) from increased TNF- $\alpha$ and interleukin- 6 and decreased adiponectin. ${ }^{4}$

Although BMI and waist circumference (WC) have traditionally been used as proxies for obesity, recent studies have suggested that abdominal visceral adipose tissue (VAT) area measured by CT might be a better indicator than BMI or WC for the risk of developing colorectal neoplasm..$^{5-7}$ Abdominal adipose tissue consists of subcutaneous adipose tissue (SAT) and VAT. An increase in VAT leads to insulin resistance and deregulated secretion of proinflammatory cytokines and adipokines, which are presumed to have a role in the development of colorectal neoplasm ${ }^{5,8}$ Several studies have shown that visceral adiposity is a risk factor for colorectal adenoma. However, previous results on the association of VAT with the risk of CRC have been inconsistent. ${ }^{9-11}$

In Korea, CRC is the second most diagnosed cancer in men, 
and the third in women. ${ }^{12}$ The proportion of overweight and obese individuals increased in 1998 to 2009, especially among men. ${ }^{13}$ From this background, we examined whether visceral adiposity serves as a risk factor for CRC and colorectal adenomas in the Korean population. In addition, we assessed the changes of VAT and SAT areas in a subset of CRC patients in the years before the diagnosis of CRC.

\section{METHODS}

\section{Study Subjects}

This was a retrospective case-control study. We enrolled the study subjects from January 2011 to December 2015 at Seoul National University Bundang Hospital. They included 151 patients with CRC, 200 patients with colorectal adenoma, and 200 healthy individuals (control group). Patients with adenoma and controls were age- and gender-matched (1:1 or 1:2 matching) with CRC patients. All the study subjects received a colonoscopy at the time of enrollment, and they all had a CT scan available for abdominal fat measurement. We excluded individuals who had suspicious hereditary CRC (i.e., familial adenomatous polyposis or hereditary non-polyposis CRC), IBD, or previous history of any cancer. We also excluded those who had significant abnormal findings including liver cirrhosis, intra-abdominal abscess, or severe inflammation on abdominal CT.

All subjects in the control and adenoma groups underwent laboratory tests, colonoscopic examination, and abdominal CT scan on the same day during a routine health check-up at Seoul National University Bundang Hospital Health Promotion Center. If the patient had no previous history of colorectal adenoma and colonoscopy showed no evidence of colorectal adenomatous polyps, the patient was classified into the control group. If colonoscopy had one or more adenomatous polyps, they were classified into the adenoma group. Patients in the CRC group were newly diagnosed with primary CRC which was pathologically confirmed at the time of enrollment. The CRC group included 46 patients with early-stage cancer (stage I) and 105 with advanced-stage cancer (stage II-IV). Among these 151 patients, 42 (17 with early-stage and 25 with advancedstage cancer) also had an abdominal CT scan available for abdominal fat measurement taken 1 to 4 years before the diagnosis of CRC (mean \pm SD of CT interval, 20.6 \pm 9.4 months) as a routine health check-up. Of these 42 patients, none had previous CT scans showing evidence of liver cirrhosis, tumor, abscess, or severe inflammation. The study protocol was approved by the Institutional Review Board of Seoul National University Hospital (IRB No. B-1511/324-111). The informed consent was waived.

\section{Clinical and Laboratory Evaluations}

A retrospective review of electronic medical records was conducted to evaluate age, gender, height, weight, WC, personal medical history, familial cancer history, and laboratory data. Venous sampling was performed after overnight fasting. The laboratory tests included total cholesterol and fasting glucose levels.

\section{Colonoscopic Examination}

Expert endoscopists performed colonoscopy with an electric video endoscope (model CF260; Olympus Optical, Tokyo, Japan). Adequate bowel preparation was confirmed by a Boston Bowel Preparation Score of $\geq 2$ in all three segments. ${ }^{14}$ Small polyps ( $<5 \mathrm{~mm}$ in diameter) were removed by biopsy. Large polyps ( $\geq 1 \mathrm{~cm}$ in diameter) were removed by polypectomy or endoscopic mucosal resection. Polyps were fixed in formaldehyde and evaluated histologically according to the World Health Organization criteria. Adenomas were recorded according to the location, size, and number of polyps. Hyperplastic polyps were excluded. Advanced adenoma was defined as adenoma $\geq 1 \mathrm{~cm}$ in diameter, $\geq 3$ adenomatous polyps, high-grade dysplasia, or adenoma containing $>25 \%$ villous components. Early-stage CRC was defined to be stage I cancer. Cancer staging was performed according to the criteria of the American Joint Committee on Cancer, 7 th version; ${ }^{15}$ T1NOM0 and T2N0M0 were classified as stage I cancer.

\section{Measurement of Abdominal Adipose Tissue}

All subjects underwent abdominal CT using a 16 or 64-detector row CT scanner (Mx8000 IDT 16 and Brilliance 64; Philips Medical Systems, Cleveland, OH, USA). The SAT and VAT areas $\left(\mathrm{cm}^{2}\right)$ were measured by a dedicated offline workstation (Aquarius 3D Workstation; TeraRecon Inc., San Mateo, CA, USA) using a mean of 3 serial slice at the umbilicus level. ${ }^{16,17}$ We predefined the adipose tissues of the software between -195 and -45 Hounsfield Units (HU), which is an adequate range of adipose tissue on CT images. ${ }^{16,18}$ Abdominal adipose tissue is divided into 2 compartments, SAT and VAT, by the parietal peritoneum. VAT is the adipose tissue inside the parietal peritoneum, excluding the paraspinal muscles and the vertebral column. SAT is the adipose tissue outside the parietal peritoneum, including the abdominal and back muscles. 


\section{Statistical Analyses}

Categorical variables are presented as number and percentage, and continuous variables are presented as mean \pm SD. The data were appropriately analyzed using chi-square test, ANOVA with post hoc Tukey honest significant difference (HSD) test, paired $t$-test, or multivariate logistic regression. An unconditional logistic regression model was applied to estimate the association between abdominal adipose tissue areas and the risks of colorectal adenoma and CRC, and was adjusted for age, gender, smoking, education level, and familial history of CRC. Differences were considered significant when $P$-values were $<0.05$. All analyses were performed using SPSS version 22.0 (IBM Corp., Armonk, NY, USA).

Table 1. Characteristics of the Study Subjects

\begin{tabular}{|c|c|c|c|c|c|}
\hline Characteristic & $\begin{array}{l}\text { Control } \\
(n=200)\end{array}$ & $\begin{array}{c}\text { Adenoma } \\
(n=200)\end{array}$ & $\begin{array}{l}\text { Early-stage CRC } \\
\qquad(n=46)^{a}\end{array}$ & $\begin{array}{l}\text { Advanced-stage } \\
\text { CRC }(n=105)^{b}\end{array}$ & $P$-value ${ }^{c}$ \\
\hline Age (yr) & $55.5 \pm 7.8$ & $54.9 \pm 7.8$ & $57.1 \pm 10.0$ & $56.3 \pm 10.0$ & 0.311 \\
\hline Male sex & $100(50.0)$ & $100(50.0)$ & $23(50.0)$ & $55(52.4)$ & 0.979 \\
\hline Height (cm) & $163.6 \pm 8.3$ & $163.8 \pm 8.5$ & $161.8 \pm 8.5$ & $161.9 \pm 7.6$ & 0.156 \\
\hline Weight (kg) & $62.8 \pm 10.9$ & $65.9 \pm 11.4^{*}$ & $63.4 \pm 10.8$ & $63.8 \pm 9.4$ & 0.040 \\
\hline $\mathrm{BMI}\left(\mathrm{kg} / \mathrm{m}^{2}\right)$ & $23.4 \pm 3.1$ & $24.4 \pm 3.1^{*}$ & $24.1 \pm 2.6$ & $24.3 \pm 3.0$ & 0.003 \\
\hline Waist circumference (cm) & $81.6 \pm 7.8$ & $84.1 \pm 7.6^{* *}$ & $82.6 \pm 7.6$ & $83.0 \pm 7.0$ & 0.016 \\
\hline \multicolumn{6}{|l|}{ Education } \\
\hline Elementary-middle & $28(14.0)$ & $23(11.5)$ & 15 (32.6) & $29(27.6)$ & $<0.001$ \\
\hline High & $35(17.5)$ & $51(25.5)$ & $11(23.9)$ & $33(31.4)$ & \\
\hline University & 78 (39.0) & $88(44.0)$ & $17(37.0)$ & $43(41.0)$ & \\
\hline Non-responder & $59(29.5)$ & $38(19.0)$ & $3(6.5)$ & 0 & \\
\hline \multicolumn{6}{|l|}{ Smoking } \\
\hline Current smoker & $34(17.0)$ & $52(26.0)$ & $15(32.6)$ & $27(25.7)$ & $<0.001$ \\
\hline Ex-smoker & $50(25.0)$ & $26(13.0)$ & $4(8.7)$ & $8(7.6)$ & \\
\hline Nonsmoker & $116(58.0)$ & $122(61.0)$ & $27(58.7)$ & $70(66.7)$ & \\
\hline \multicolumn{6}{|l|}{ Comorbidity } \\
\hline Hypertension & $44(22.0)$ & $57(28.5)$ & $13(28.3)$ & $28(26.7)$ & 0.483 \\
\hline Diabetes & $15(7.5)$ & $23(11.5)$ & $4(8.7)$ & $19(18.1)$ & 0.043 \\
\hline Family history of $\mathrm{CRC}$ among first-degree relatives & $12(6.0)$ & $17(8.5)$ & $1(2.2)$ & $6(5.7)$ & 0.406 \\
\hline Advanced adenomatous polyp & - & $48(24.0)$ & - & - & - \\
\hline 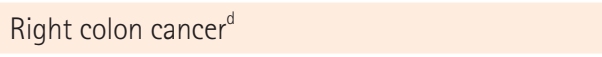 & - & - & $10(21.7)$ & $35(33.3)$ & 0.152 \\
\hline Serum total cholesterol (mg/dL) & $200.0 \pm 35.3$ & $208.9 \pm 38.5$ & $180.3 \pm 35.1^{* *}$ & $173.1 \pm 36.3^{* * *}$ & $<0.001$ \\
\hline Plasma fasting glucose (mg/dL) & $92.8 \pm 20.0$ & $98.1 \pm 26.8$ & $106.5 \pm 37.6^{* *}$ & $107.1 \pm 21.2^{* * *}$ & $<0.001$ \\
\hline VAT area $\left(V_{1} \mathrm{~cm}^{2}\right)$ & $94.6 \pm 46.6$ & $116.8 \pm 49.5^{* * *}$ & $110.4 \pm 56.8$ & $99.7 \pm 49.3$ & $<0.001$ \\
\hline SAT area $\left(\mathrm{S}, \mathrm{cm}^{2}\right)$ & $139.7 \pm 57.1$ & $151.6 \pm 56.3$ & $137.9 \pm 49.7$ & $135.7 \pm 52.4$ & 0.051 \\
\hline Total fat area $\left(\mathrm{V}+\mathrm{S}, \mathrm{cm}^{2}\right)$ & $234.3 \pm 88.8$ & $268.4 \pm 88.4^{* * *}$ & $248.3 \pm 78.9$ & $235.4 \pm 80.2$ & $<0.001$ \\
\hline visceral-to-total fat ratio, V/(V+S) & $39.6 \pm 11.3$ & $43.1 \pm 10.8^{*}$ & $43.3 \pm 13.8$ & $41.7 \pm 12.8$ & 0.018 \\
\hline
\end{tabular}

Values are presented as the mean \pm SD or number (\%).

a Stage I cancers.

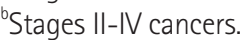

${ }^{\mathrm{C}} P$-values were calculated using chi-square test (categorical variables) or ANOVA (continuous variables).

${ }^{d}$ Right-sided colon cancer is a cancer derived from the embryologic midgut including the cecum, ascending colon, and transverse colon.

CRC, colorectal cancer; VAT, visceral adipose tissue; SAT, subcutaneous adipose tissue; V/(V+S), visceral adipose tissue area/([visceral adipose tissue area]+[subcutaneous adipose tissue area]).

${ }^{*} P<0.05,{ }^{* *} P<0.01,{ }^{* *} P<0.001$ compared with control group using ANOVA post hoc analysis using Turkey honest significant difference test. Differences were considered significant when $P$-values were $<0.05$. 


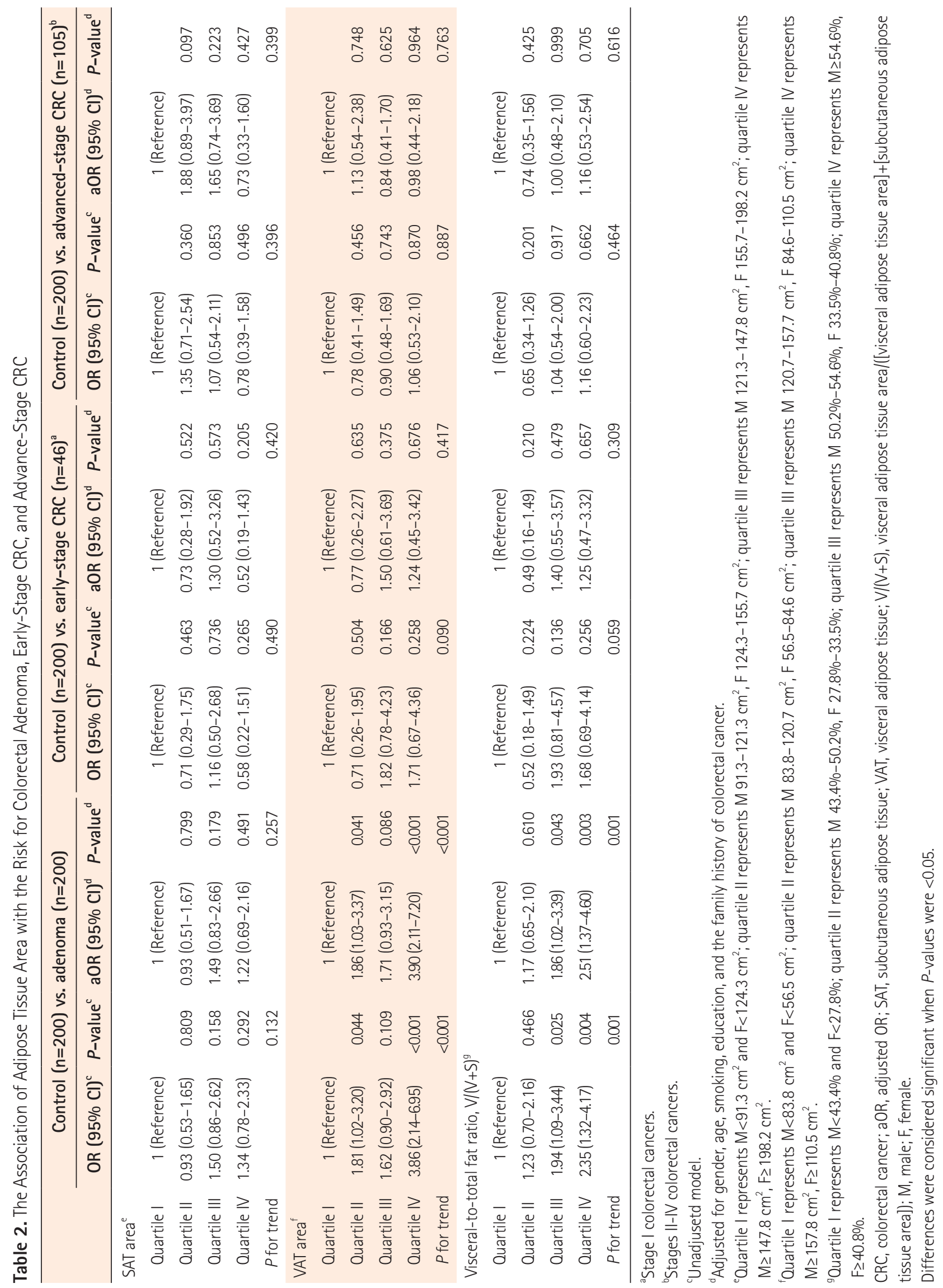




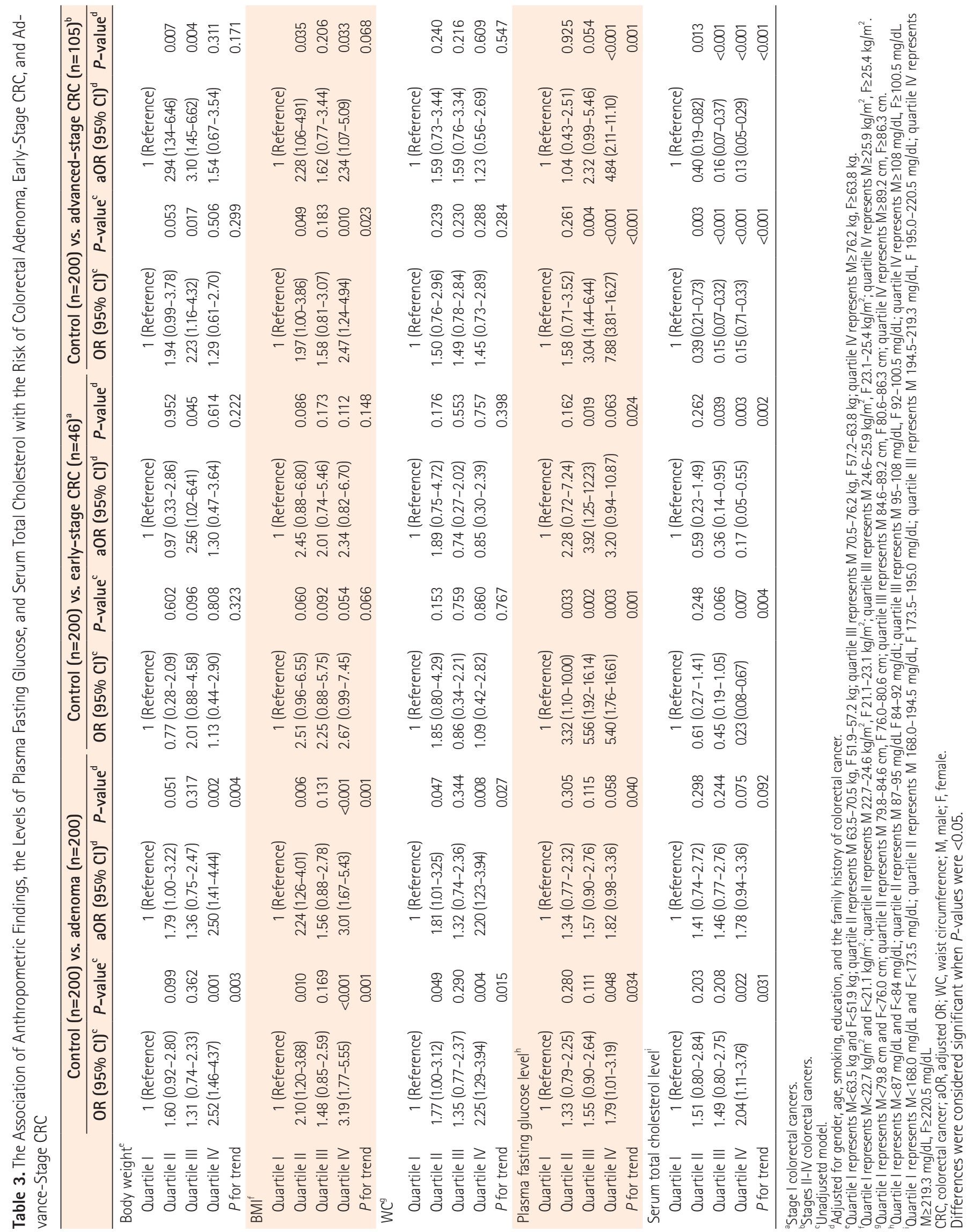




\section{RESULTS}

\section{Characteristics of the Study Subjects}

Table 1 shows the baseline characteristics of the study subjects. The adenoma group had a significantly increased body weight, BMI, WC, VAT area, total fat area, and visceral-to-total fat ratio compared with the control group (all $P<0.05$ by ANOVA post hoc analysis using Tukey HSD test.) The means \pm SD of the VAT areas were $94.6 \pm 46.6 \mathrm{~cm}^{2}$ in the control group, $116.8 \pm$ $49.5 \mathrm{~cm}^{2}$ in adenoma group, $110.4 \pm 56.8 \mathrm{~cm}^{2}$ in the early-stage CRC group, and $99.7 \pm 49.3 \mathrm{~cm}^{2}$ in the advanced-stage CRC group $(P<0.004$ by ANOVA). SAT areas were not different among the 4 groups $(P>0.05)$.

In contrast, fasting plasma glucose levels were significantly higher in the CRC groups (mean \pm SD, $106.5 \pm 37.6 \mathrm{mg} / \mathrm{dL}$ and $107.1 \pm 21.2 \mathrm{mg} / \mathrm{dL}$ in the early- and advanced-stage CRC groups, respectively) than in the control group $(92.8 \pm 20.0 \mathrm{mg} / \mathrm{dL}, P<$ $0.01)$, and serum total cholesterol levels were significantly lower in the CRC groups $(180.3 \pm 35.1 \mathrm{mg} / \mathrm{dL}$ and $173.1 \pm 36.3 \mathrm{mg} /$ $\mathrm{dL}$ in the early- and advanced-stage CRC groups, respectively) than in the control group $(200.0 \pm 35.3 \mathrm{mg} / \mathrm{dL}, P<0.01)$ (Table 1$)$.

\section{The Risk of Colorectal Adenoma and CRC by Adipose Tissue Area and Fasting Plasma Glucose Level}

Next, we analyzed whether the SAT area VAT area, and the visceral-to-total fat ratio were risk factors of CRC or adenoma using quartile categories of these variables by logistic regression analysis models. We found that the risk of colorectal adenoma positively correlated not only with the VAT area but also the visceral-to-total fat ratio ( $P$ for trend $<0.01$ ) (Table 2 ). However, there was no association of the SAT area with the risk of adenoma $(P>0.05)$. In addition, there was no trend found with regard to the association between these variables and the risk of CRC $(P>0.05)$.

Moreover, the risk of adenoma increased with increases of body weight, BMI, and WC ( $P$ for trend $<0.05$ ), but that of CRC did not $(P>0.05)$ (Table 3$)$. Interestingly, not only the risk of adenoma but also that of CRC significantly increased along with the fasting plasma glucose level $(P$ for trend $<0.05$ ).

We also compared the adipose tissue areas from the CT images taken at diagnosis with those from CT images taken 1 to 4 years before the diagnosis of CRC in 42 CRC patients (Table 4). In the patients with early-stage CRC $(n=17)$, the VAT areas were decreased at diagnosis, but the SAT areas were unchanged. Thus visceral-to-total fat ratio at diagnosis was significantly lower than that before diagnosis ( $46.6 \%$ vs. $50.7 \%, P=0.018$ by
Table 4. Comparison of Adipose Tissue Area by the Different Time Points of the CT Scan in the Same Patients with CRC $(n=42)$

\begin{tabular}{lccc}
\hline & \multicolumn{2}{c}{ Timing of CT scan } & \\
\cline { 2 - 3 } Stage & $\begin{array}{c}1-4 \text { Years } \\
\text { before } \\
\text { diagnosis }\end{array}$ & $\begin{array}{c}\text { At the time } \\
\text { of diagnosis }\end{array}$ & P-value ${ }^{\mathrm{a}}$ \\
\hline Early-stage CRC $(\mathrm{n}=17)$ & $137.0 \pm 62.2$ & $121.3 \pm 74.3$ & 0.081 \\
VAT area $\left(\mathrm{V}, \mathrm{cm}^{2}\right)$ & $130.9 \pm 55.7$ & $131.7 \pm 66.0$ & 0.888 \\
SAT area $\left(\mathrm{S}, \mathrm{cm}^{2}\right)$ & $267.9 \pm 84.6$ & $253.0 \pm 109.3$ & 0.252 \\
Total fat area $\left(\mathrm{cm}^{2}\right)$ & $50.7 \pm 13.3$ & $46.6 \pm 15.0$ & 0.018 \\
V/(V+S), \% & $149.0 \pm 70.6$ & $130.7 \pm 59.8$ & 0.034 \\
Advanced-stage CRC $(\mathrm{n}=25)$ & $151.3 \pm 47.7$ & $131.1 \pm 44.9$ & $<0.001$ \\
VAT area $\left(\mathrm{V}, \mathrm{cm}^{2}\right)$ & $300.3 \pm 75.1$ & $261.8 \pm 82.3$ & $<0.001$ \\
SAT area $\left(\mathrm{S}, \mathrm{cm}^{2}\right)$ & $53.4 \pm 27.1$ & $49.3 \pm 13.0$ & 0.414 \\
Total fat area $\left(\mathrm{cm}^{2}\right)$ & & & \\
V/(V+S), \% & & & \\
\hline
\end{tabular}

${ }^{a} P$-values were calculated using paired $t$-test.

CRC, colorectal cancer; VAT, visceral adipose tissue; SAT, subcutaneous adipose tissue; $V /(V+S)$, visceral adipose tissue area/([visceral adipose tissue area]+[subcutaneous adipose tissue area]).

Differences were considered significant when $P$-values were $<0.05$.

paired $t$-test) (Table 3). Among patients with advanced-stage CRC $(\mathrm{n}=25)$, however, the SAT area and the VAT area were both decreased (all $P<0.001$ ), so the ratio for visceral-to-total fat was not different before and at diagnosis.

\section{DISCUSSION}

In the present study, visceral obesity was an independent risk factor of colorectal adenoma, along with body weight, BMI, and WC. In contrast, subcutaneous fat was not associated with the risk of adenoma (Table 2). Our findings are consistent with the findings of previous studies.

To date, several indicators have been suggested to determine obesity. Among them, both BMI and body weight appear to reflect the amount of whole body fat, whereas WC and waist to hip ratio correspond to visceral fat. In this study, we adopted a technique using CT images to measure the abdominal adipose tissue areas which has been standardized and validated in previous studies. ${ }^{19,20}$ The VAT area is regarded as a better indicator for evaluating the risk of CRC by obesity than other anthropometric markers. ${ }^{21}$

There has been strong evidence that visceral obesity increases the risk of colorectal adenoma. ${ }^{5,6,11,22}$ However, there are limited reports on the association between visceral obesity 
and CRC, and the results are inconsistent. ${ }^{10,23}$ In this study, we found only insignificant results with regard to the association between obesity markers and the risk of CRC (Tables 2 and 3). In early-stage CRC, body weight and BMI increased along with the risk of CRC, although it was not statistically significant ( $P$ for trend $>0.05$ ) (Table 3 ). In advanced-stage $C R C$, the association of BMI with the risk of CRC showed only marginal significance ( $P$ for trend $=0.066$ ). In both the early- and advancedstage CRC groups, there was no association observed between the SAT and VAT areas and the risk of CRC (Table 2).

We speculated that the negative results in the CRC groups might be attributed to the loss of the adipose tissue in the late stages of colorectal carcinogenesis. However, there are other possibilities. In Western population, adenoma-carcinoma sequence is well-established and up to $\sim 90 \%$ of CRC cases occurs following this sequence. However, the adenoma-carcinoma sequence in colorectal carcinogenesis might be less dominant in the Asian population. That is, CRC can develop directly from the normal colonic mucosa without undergoing the adenomatous stage in non-obese individuals (de novo pathway hypothesis). ${ }^{24}$

To clarify this issue, we compared the CT scans taken at the diagnosis of CRC and those taken 1 to 4 years before diagnosis in a subset of the CRC patients $(\mathrm{n}=42)$ (Table 4). Interestingly, we found that the abdominal adipose tissue areas significantly decreased in the years prior to CRC. In patients with early-stage CRC, the VAT area had decreased at the early stages of adenoma-carcinoma sequence, whereas the SAT area was unchanged. Therefore, the ratio for visceral-to-total fat significantly decreased (Table 3). In advanced-stage CRC patients, however, not only visceral fat but also subcutaneous fat decreased ( $P$-values $<0.001$ ) (Table 3).

Our findings are consistent with the findings of previous studies that evaluated changes in the abdominal adipose tissue areas in advanced cancer patients. These studies reported a rapid loss of adipose tissue as cancer progresses. ${ }^{25}$ In addition, a recent study performed longitudinal analyses of CT images in patients with advanced gastrointestinal cancers, including CRC, and found that the loss of VAT preceded that of SAT. ${ }^{26}$ VAT and SAT differ not only by anatomic location but also by endocrine function, adipokine secretion, lipolytic activity, and the response to insulin. ${ }^{27} \mathrm{~A}$ previous study reported that saturated fatty acids were higher and monounsaturated fatty acids were lower in visceral fat than in subcutaneous fat. ${ }^{28}$ VAT has a unique architecture in that it is highly cellular, hypervascular and innervated and it contains various cells with inflammato- ry and immunological functions. ${ }^{29}$ Differential fat loss between VAT and SAT might be related to the production of carcinogenic mediators, which might lead to the progression of colorectal carcinogenesis. ${ }^{26,30}$

Based on these previous findings, we hypothesized a new role for VAT in colorectal carcinogenesis. Visceral fat accumulation likely has a role in adenoma formation. However, lipolysis of the visceral fat occurs later, and it may be important in the progression from adenoma to carcinoma. In advancedstage CRC, the loss of subcutaneous fat occurs, which is probably owing to cancer-related cachexia. We acknowledge that our results should be confirmed in large prospective cohort studies including the patients with both colorectal adenoma and CRC. Nevertheless, the differential loss of VAT and SAT in early-stage CRC was remarkable even with the small number of patients included in our study.

In this study, fasting plasma glucose level was significantly increased in both adenoma and CRC groups (Table 3). The risk of colorectal adenoma increased along with fasting plasma glucose level $(P$ for trend $=0.040)$ (Table 3 ), but the association was more prominent in the early- and advanced-CRC groups ( $P$ for trend $=0.024$ and $P$ for trend $=0.001$ in the earlyand advanced-CRC groups, respectively.) Our findings of the relationship between serum glucose level and the risk of CRC were consistent with the findings of previous studies. ${ }^{31} \mathrm{Im}$ paired fasting glucose and/or hyperinsulinemia are considered as risk factors for the development of CRC. ${ }^{32}$ Insulin resistance results in hyperinsulinemia which is associated with increased levels of insulin-like growth factor-1, an anti-apoptotic and mitogenic factor. ${ }^{33}$ Previous studies have reported that type 2 diabetes is associated with an increased risk of CRC. ${ }^{34,35}$ A recent meta-analysis showed an increase of $29 \%$ in the risk of CRC among patients with impaired fasting glucose, impaired glucose tolerance, or overt type 2 diabetes mellitus. ${ }^{36}$

Serum total cholesterol level showed an insignificant positive correlation with the risk of adenoma $(P$ for trend $=0.092)$ (Table 3). However, it showed a negative correlation with the risk of CRC ( $P$ for trend $<0.01$ ). To date, the relationship between dyslipidemia and colorectal adenoma is nebulous. ${ }^{37} \mathrm{In}$ the case of $\mathrm{CRC}$, the negative correlations may be attributed to cancer-related cachexia.

This study has the following limitations. First, this study was designed to be a retrospective case-control study. The control and adenoma groups were enrolled from the health promotion center, and the CRC groups were enrolled from the gastroenterology and general surgery departments. Thus, there might 
be selection bias. For example, there was a significant difference observed in education level among the groups (Table 1). Second, this study was retrospective, and information on some of the risk factors for CRC, such as red meat consumption and alcohol intake amount, was not available. Third, there were only 42 CRC patients who had CT images available both at and prior to diagnosis. In addition, there was no information available on the endoscopic findings at the time of the CT scan prior to diagnosis, such as the number of colorectal adenomas. This significantly weakens the clinical importance of our novel findings. However, to eliminate any biases, we excluded any patients who had undergone abdominal CT scan for the evaluation of their abdominal symptoms, as well as those who had significant abnormal findings in a previous CT scan that might affect the quantities of abdominal adipose tissues. Fourth, it has been suggested that volumetric measure of VAT might be more accurate than VAT area. However, the technique we used for the measurement of the VAT area has been standardized and validated in previous studies. ${ }^{19,20}$ Fifth, data on serum triglycerides, high-density lipoprotein-cholesterol levels, and plasma insulin level were not available, especially in the CRC groups. The associations between serum triglycerides, low- and high-density lipoprotein-cholesterols and the risk of CRC are still inconclusive ${ }^{36}$ Hence, further studies are warranted in this issue.

To conclude, the accumulation of visceral fat is related to the development of colorectal adenoma, but the loss of visceral fat is observed beginning in the early stage of CRC. In contrast, the loss of subcutaneous fat occurs in the advanced stages of CRC. In addition, impaired fasting glucose may have a role in the development of CRC. Further studies are warranted in on this issue.

\section{FINANCIAL SUPPORT}

The authors received no financial support for the research, authorship, and/or publication of this article.

\section{CONFLICT OF INTEREST}

No potential conflict of interest relevant to this article was reported.

\section{AUTHOR CONTRIBUTION}

Data collection: Jung IS, Jo HJ. Data analysis and study design: Shin CM. Study concept: Kim N, Lee DH. Writing - draft and tables; abdominal fat measurement: Jung IS. Manuscript supervision: Shin CM, Park SJ, Jo HJ. Table supervision: Park SJ. Critical revision of the manuscript: Park YS, Yoon H. Draft revision: Shin CM, Park SJ, Park YS, Yoon H, Kim N, Lee DH. Approval of final manuscript: all authors.

\section{REFERENCES}

1. Frezza EE, Wachtel MS, Chiriva-Internati M. Influence of obesity on the risk of developing colon cancer. Gut 2006;55:285291.

2. Bardou M, Barkun AN, Martel M. Obesity and colorectal cancer. Gut 2013;62:933-947.

3. Colangelo LA, Gapstur SM, Gann PH, Dyer AR, Liu K. Colorectal cancer mortality and factors related to the insulin resistance syndrome. Cancer Epidemiol Biomarkers Prev 2002;11:385391.

4. Chan AT, Giovannucci EL. Primary prevention of colorectal cancer. Gastroenterology 2010;138:2029-2043.e10.

5. Otake S, Takeda H, Suzuki Y, et al. Association of visceral fat accumulation and plasma adiponectin with colorectal adenoma: evidence for participation of insulin resistance. Clin Cancer Res 2005;11:3642-3646.

6. Oh TH, Byeon JS, Myung SJ, et al. Visceral obesity as a risk factor for colorectal neoplasm. J Gastroenterol Hepatol 2008;23: 411-417.

7. Yamamoto S, Nakagawa T, Matsushita Y, et al. Visceral fat area and markers of insulin resistance in relation to colorectal neoplasia. Diabetes Care 2010;33:184-189.

8. Prieto-Hontoria PL, Pérez-Matute P, Fernández-Galilea M, Bustos M, Martínez JA, Moreno-Aliaga MJ. Role of obesity-associated dysfunctional adipose tissue in cancer: a molecular nutrition approach. Biochim Biophys Acta 2011;1807:664-678.

9. Nam SY, Kim BC, Han KS, et al. Abdominal visceral adipose tissue predicts risk of colorectal adenoma in both sexes. Clin Gastroenterol Hepatol 2010;8:443-450.e2.

10. Choe EK, Kim D, Kim HJ, Park KJ. Association of visceral obesity and early colorectal neoplasia. World J Gastroenterol 2013; 19:8349-8356.

11. Nagata N, Sakamoto K, Arai T, et al. Visceral abdominal fat measured by computed tomography is associated with an increased risk of colorectal adenoma. Int J Cancer 2014;135:2273-2281.

12. Shin A, Kim KZ, Jung KW, et al. Increasing trend of colorectal cancer incidence in Korea, 1999-2009. Cancer Res Treat 2012; 44:219-226.

13. Kang HT, Shim JY, Lee HR, Park BJ, Linton JA, Lee YJ. Trends 
in prevalence of overweight and obesity in Korean adults, 19982009: the Korean National Health and Nutrition Examination Survey. J Epidemiol 2014;24:109-116.

14. Rex DK, Petrini JL, Baron TH, et al. Quality indicators for colonoscopy. Gastrointest Endosc 2006;63(4 Suppl):S16-S28.

15. Edge SB, Compton CC. The American Joint Committee on Cancer: the 7th edition of the AJCC cancer staging manual and the future of TNM. Ann Surg Oncol 2010;17:1471-1474.

16. Borkan GA, Gerzof SG, Robbins AH, Hults DE, Silbert CK, Silbert JE. Assessment of abdominal fat content by computed tomography. Am J Clin Nutr 1982;36:172-177.

17. Yoshizumi T, Nakamura T, Yamane M, et al. Abdominal fat: standardized technique for measurement at CT. Radiology 1999;211:283-286.

18. Sjöström L, Kvist H, Cederblad A, Tylén U. Determination of total adipose tissue and body fat in women by computed tomography, 40K, and tritium. Am J Physiol 1986;250(6 Pt 1): E736-E745.

19. Goodpaster BH. Measuring body fat distribution and content in humans. Curr Opin Clin Nutr Metab Care 2002;5:481-487.

20. Tokunaga K, Matsuzawa Y, Ishikawa K, Tarui S. A novel technique for the determination of body fat by computed tomography. Int J Obes 1983;7:437-445.

21. Keum N, Lee DH, Kim R, Greenwood DC, Giovannucci EL. Visceral adiposity and colorectal adenomas: dose-response meta-analysis of observational studies. Ann Oncol 2015;26: 1101-1109.

22. Kang HW, Kim D, Kim HJ, et al. Visceral obesity and insulin resistance as risk factors for colorectal adenoma: a cross-sectional, case-control study. Am J Gastroenterol 2010;105:178187.

23. Lee JY, Lee HS, Lee DC, et al. Visceral fat accumulation is associated with colorectal cancer in postmenopausal women. PLoS One 2014;9:e110587.

24. Sung JJ, Lau JY, Goh KL, Leung WK; Asia Pacific Working Group on Colorectal Cancer. Increasing incidence of colorectal cancer in Asia: implications for screening. Lancet Oncol 2005;6: 871-876.

25. Lieffers JR, Mourtzakis M, Hall KD, McCargar LJ, Prado CM, Baracos VE. A viscerally driven cachexia syndrome in patients with advanced colorectal cancer: contributions of organ and tumor mass to whole-body energy demands. Am J Clin Nutr 2009;89:1173-1179.

26. Ebadi M, Baracos VE, Bathe OF, Robinson LE, Mazurak VC.
Loss of visceral adipose tissue precedes subcutaneous adipose tissue and associates with n-6 fatty acid content. Clin Nutr 2016;35:1347-1353.

27. Wajchenberg BL. Subcutaneous and visceral adipose tissue: their relation to the metabolic syndrome. Endocr Rev 2000;21: 697-738.

28. Garaulet M, Pérez-Llamas F, Pérez-Ayala M, et al. Site-specific differences in the fatty acid composition of abdominal adipose tissue in an obese population from a Mediterranean area: relation with dietary fatty acids, plasma lipid profile, serum insulin, and central obesity. Am J Clin Nutr 2001;74:585-591.

29. Kursawe R, Eszlinger M, Narayan D, et al. Cellularity and adipogenic profile of the abdominal subcutaneous adipose tissue from obese adolescents: association with insulin resistance and hepatic steatosis. Diabetes 2010;59:2288-2296.

30. Murff HJ, Shu XO, Li H, et al. A prospective study of dietary polyunsaturated fatty acids and colorectal cancer risk in Chinese women. Cancer Epidemiol Biomarkers Prev 2009;18:22832291.

31. Jee SH, Ohrr H, Sull JW, Yun JE, Ji M, Samet JM. Fasting serum glucose level and cancer risk in Korean men and women. JAMA 2005;293:194-202.

32. Ozasa K, Ito Y, Suzuki K, et al. Glucose intolerance and colorectal cancer risk in a nested case-control study among Japanese People. J Epidemiol 2005;15 Suppl 2:S180-S184.

33. Vigneri PG, Tirrò E, Pennisi MS, et al. The insulin/IGF system in colorectal cancer development and resistance to therapy. Front Oncol 2015;5:230.

34. Peeters PJ, Bazelier MT, Leufkens HG, de Vries F, De Bruin ML. The risk of colorectal cancer in patients with type 2 diabetes: associations with treatment stage and obesity. Diabetes Care 2015;38:495-502.

35. Yuhara H, Steinmaus C, Cohen SE, Corley DA, Tei Y, Buffler PA. Is diabetes mellitus an independent risk factor for colon cancer and rectal cancer? Am J Gastroenterol 2011;106:19111921.

36. Esposito K, Chiodini P, Capuano A, et al. Colorectal cancer association with metabolic syndrome and its components: a systematic review with meta-analysis. Endocrine 2013;44:634647.

37. Suchanek S, Grega T, Ngo O, et al. How significant is the association between metabolic syndrome and prevalence of colorectal neoplasia? World J Gastroenterol 2016;22:8103-8111. 